\title{
SISTEM INFORMASI GEOGRAFIS PEMETAAN WARGA NEGARA ASING
}

\author{
${ }^{1)}$ Reni Yunita, ${ }^{2)}$ Samsudin, ${ }^{3)}$ Raissa Amanda Putri \\ Sistem Informasi Fakultas Sains dan Teknologi Universitas Islam Negeri Sumatera Utara Medan \\ JL. Lapangan Golf, Desa Durian Jangak - Kabupaten Deli Serdang - Indonesia \\ E-mail : reni.yunita@uinsu.ac.id ${ }^{4)}$, samsudin@uinsu.ac.id ${ }^{5)}$,raissa.ap@ uinsu.ac.id $\left.{ }^{6}\right)$
}

\begin{abstract}
ABSTRAK
WNA (Warga Negara Asing) di data pada sebuah intansi pemerintah yaitu Kantor Imigrasi Kelas II Tanjung Balai Asahan pada bidang Intelijen dan Penindakan Keimigrasian. Informasi yang tersedia di Imigrasi tersebut hanya sebatas data yang berbentuk tabel yang berisikan informasi dari WNA tersebut, dan tidak tersedia gambaran yang jelas secara geografis mengenai lokasi WNA. Sehingga dibutuhkan suatu sistem informasi geografis mengenai persebaran WNA. Penelitian ini menggunakan Leaflet untuk visualisasi peta. Adanya Sistem informasi geografis ini dapat memberikan informasi mengenai WNA kepada masyarakat guna menyosialisasikan keberadaan WNA, dan juga dapat melaporkan keberadaan WNA yang belum terdaftar, serta dapat mendukung pelayanan keimigrasian terhadap pengawasan WNA.
\end{abstract}

Kata Kunci : Sistem Informasi Geografis, Warga Negara Asing, Leaflet, Quantum GIS.

\begin{abstract}
Foreign Citizens are recorded in a government agency, namely the Class II Immigration Office of Tanjung Balai Asahan in the field of Immigration Intelligence and Enforcement. The information available at the Immigration Office is limited to data in the form of tables containing information from the foreigner, so that when the data increases, it will be difficult for officers to search for foreigner data. Therefore, we need a geographic information system regarding the distribution of foreigners. This research uses Leaflet, and Quantum GIS for map visualization. The existence of this geographic information system can provide information about foreigners to the public in order to socialize the presence of foreigners, and can also report the presence of foreigners who have not been registered, and can support immigration services for the supervision of foreigners.
\end{abstract}

Keywords: GIS, Foreign Citizens, Leaflet, Quantum GIS.

\section{PENDAHULUAN}

Teknologi informasi sudah menjadi hal yang sangat umum dikalangan masyarakat saat ini, oleh sebab itu keberadaan sebuah teknologi informasi yang cepat dan mudah diharapkan dapat mengolah sebuah informasi yang diinginkan. Dalam hal ini keberadaan sistem informasi menghadirkan sebuah inovasi baru, yaitu penggabungan antara sistem informasi dan illmu geografis dalam pengelolaan informasi yaitu Sistem Informasi Geografis (SIG). Warga Negara Asing yang keberadaanya saat ini di Kota Tanjung Balai dan Kabupaten Asahan, di data pada sebuah intansi pemerintah yaitu Kantor Imigrasi Kelas II Tanjung Balai Asahan, pada bidang Intelijen dan Penindakan Keimigrasian yang bertugas memberikan dokumen keimigrasian dan pengawasan orang asing atau WNA. Informasi yang tersedia di Imigrasi tersebut hanya sebatas data yang berbentuk tabel yang berisikan informasi dari WNA tersebut, sehingga ketika data semakin bertambah banyak akan menyulitkan petugas dalam melakukan pencarian data WNA. Salah satu faktor dilakukannya pengawasan terhadap orang asing yang dilakukan pada Kantor Imigrasi Kelas II Tanjung Balai Asahan adalah kurangnya kesadaran dari pihak perusahaan pengguna tenaga ahli asing dalam melakukan transparansi mengenai keberadaan serta kegiatan tenaga ahli asing yang bekerja pada perusahaanya, dan juga sebagian WNA yang belum mendaftarkan dirinya sebagai WNA yang tinggal di Indonesia, Oleh sebab itu dibutuhkan suatu sistem informasi geografis mengenai persebaran WNA. Sistem informasi geografis yang dihasilkan menggunakan Leaflet dan QGIS untuk visualisasi peta, dan framework Laravel dalam pembuatan sistem.

\section{METODE}


Metode penelitian yang digunakan adalah metode kualitatif, yaitu meliputi:

1.Observasi, dilakukan oleh peneliti pada Kantor Imigrasi Kelas II Tanjung Balai Asahan. Observasi dilakukan pada bidang Intelijen dan Penindakan Keimigrasian yang bertugas memberikan dokumen keimigrasian dan pengawasan orang asing atau WNA.

2.Wawancara, merupakan salah satu teknik pengumpulan data dengan cara komunikasi dengan narasumber yaitu Bapak Iskandar, SS. Dimana Bapak Iskandar merupakan Kasubsi Intelijen yang bertugas sebagai Tim Pora atau tim pengawasan orang asing.

3.Studi Pustaka, kegiatan menelaah informasi yang relevan dengan topik baik dalam format buku, jurnal atau pun skripsi.

\section{Kerangka Kerja Penelitian}

Waterfall adalah metode yang digunakan para peneliti sistem dalam melakukan pengembangan software[1]. kerangka kerja penelitian seperti pada gambar berikut ini.

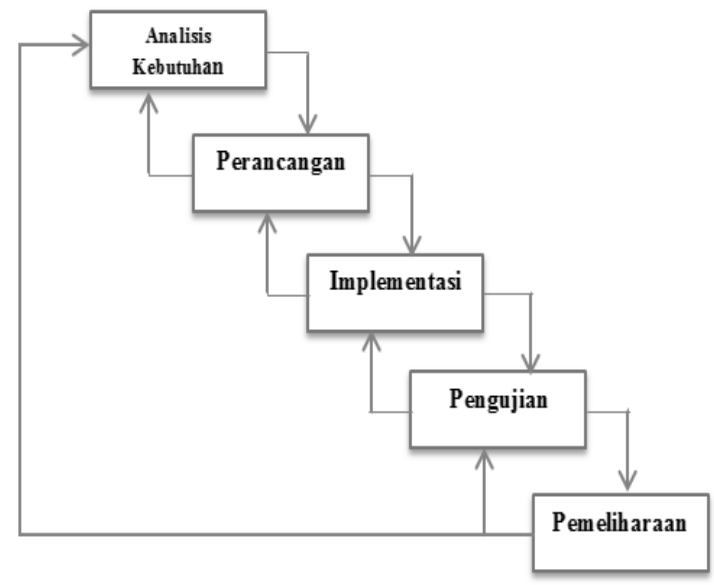

Gambar 1. Kerangka Kerja Penelitian

\section{HASIL}

\section{Tabel Perancangan Database}

Tabel 1. Tabel User

\begin{tabular}{llll} 
No. & $\begin{array}{l}\text { Nama } \\
\text { Field }\end{array}$ & $\begin{array}{l}\text { Tipe } \\
\text { Data }\end{array}$ & Ukuran \\
\hline 1. & id & int & 5 \\
\hline 2. & name & varchar & 100 \\
\hline 3. & email & varchar & 50 \\
\hline 4. & password & varchar & 50 \\
\hline 5. & foto & varchar & 100
\end{tabular}

Tabel 2. Tabel Kabupaten/Kota

No. Nama Tipe Data Ukuran

\begin{tabular}{llll}
\hline 1. & id_kabkot & int & 5 \\
\hline 2. & kabkot & varchar & 100 \\
\hline 3. & polygon & longtext & - \\
\hline 4. & warna & varchar & 15
\end{tabular}

Tabel 3. Tabel Lokasi WNA

No. Nama Field Tipe Data Ukuran

\begin{tabular}{llll}
\hline 1. & id_lokasi & int & 5 \\
\hline 2. & alamat & varchar & 100 \\
\hline 3. & sponsor & varchar & 100 \\
\hline 4. & id_kabkot & varchar & 3 \\
\hline 5. & id_wna & varchar & 3 \\
\hline 6. & posisi & varchar & 50 \\
\hline 7. & foto & varchar & 100
\end{tabular}

\section{Rancangan Interface}

Rancangan interface atau antar-muka berupa komunikasi antar pengguna dengan sistem, yang gunanya untuk menampilkan penjelasan sistem secara keseluruhan step by step sehingga user mengerti apa yang akan dilakukan terhadap sistem tersebut. 


\section{Struktur Menu}

Berikut ini adalah gambaran struktur menu apa saja yang dapat dijalankan oleh pengguna (user).

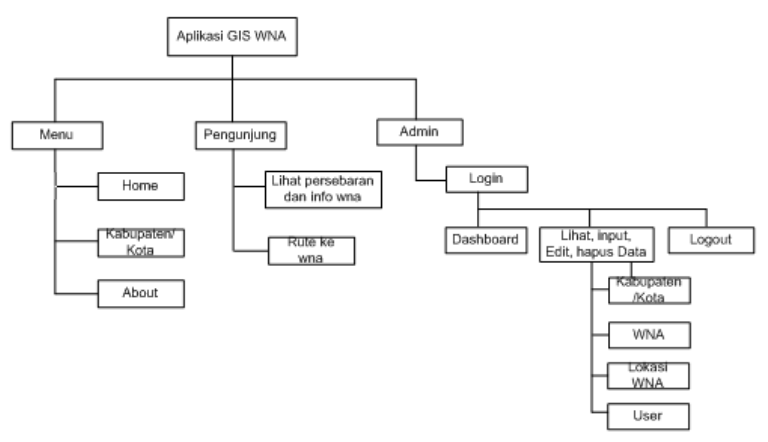

Gambar 2. Struktur Menu

\section{UseCase Diagram}

Usecase diagram yaitu diagram yang memperlihatkan urutan aktifitas proses secara urut yang ada pada sistem. Kesimpulannya, pasa usecase terdapat aktor, dimana aktor tersebutlah yang nantinya akan memperlihatkan kepada pengguna yang akan menjalankan sistem, atau bisa dibilang sebagai orang yang berinteraksi dengan sistem yang akan dibuat[2].

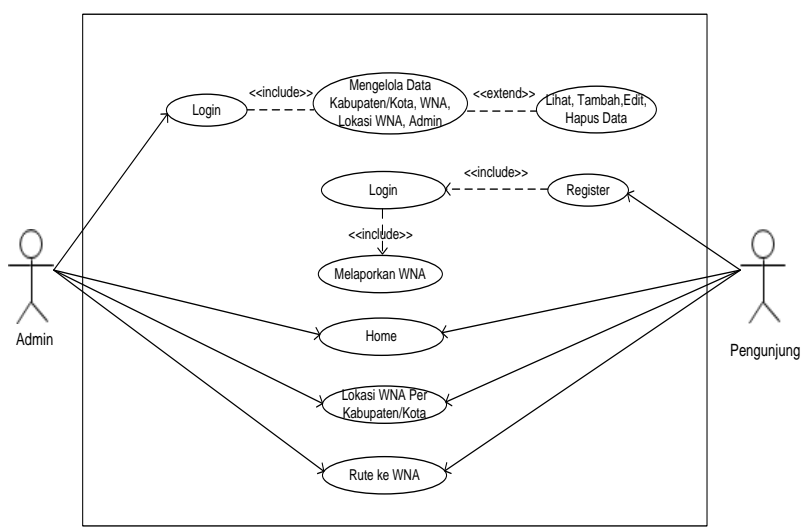

Gambar 3. UseCase Diagram

\section{Class Diagram}

Class diagram adalah jenis diagram yang digunakan untuk memberikan sebuah gambaran mengenai sistem maupun relasirelasi yang terdapat pada sistem tersebut.

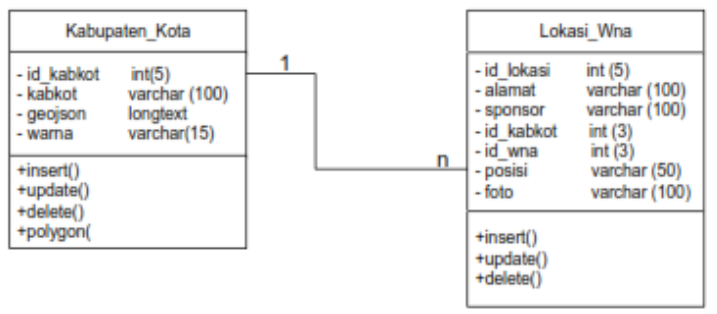

Gambar 4. UseCase Diagram

\section{Activity Diagram}

Activity diagram adalah diagram yang menggambarkan aktivitas-aktivitas yang dapat dilakukan oleh sistem, aktivitas nya disini berupa menu-menu sehingga dapat membantu dalam memahami proses sistem secara keseluruhan[4].

\section{Activity Diagram Pengelolaan Data WNA}

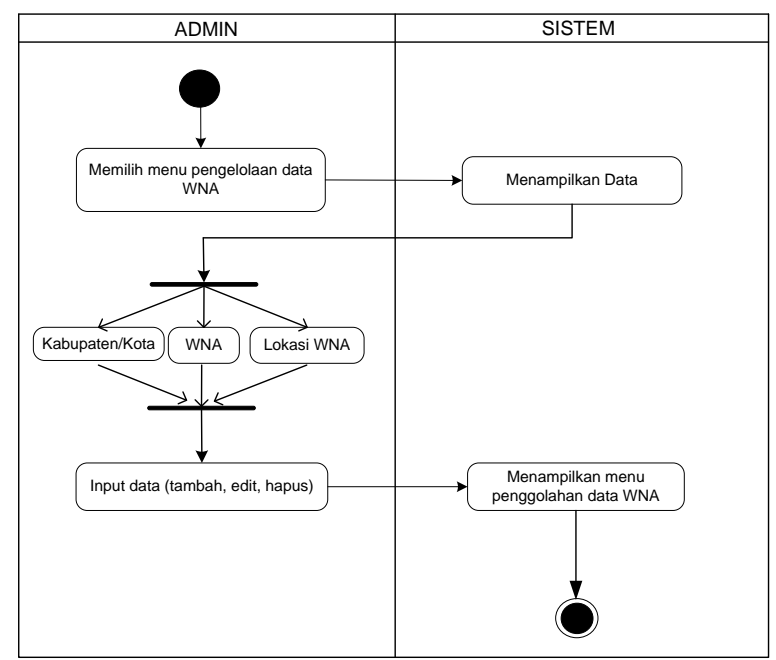

Gambar 5. Pengelolaan data WNA Activity pengelolaan data WNA diatas merupakan aktifitas yang menambahkan, mengedit dan hapus data WNA, pengolahan data WNA meliputi data kabupaten, data wna, data lokasi dan juga data user.

\section{Sequence Diagram}

Sequence diagram merupakan gambar kegiatan aktor berdasarkan rangkaian urutan waktu penggunaan sistem[3]. 


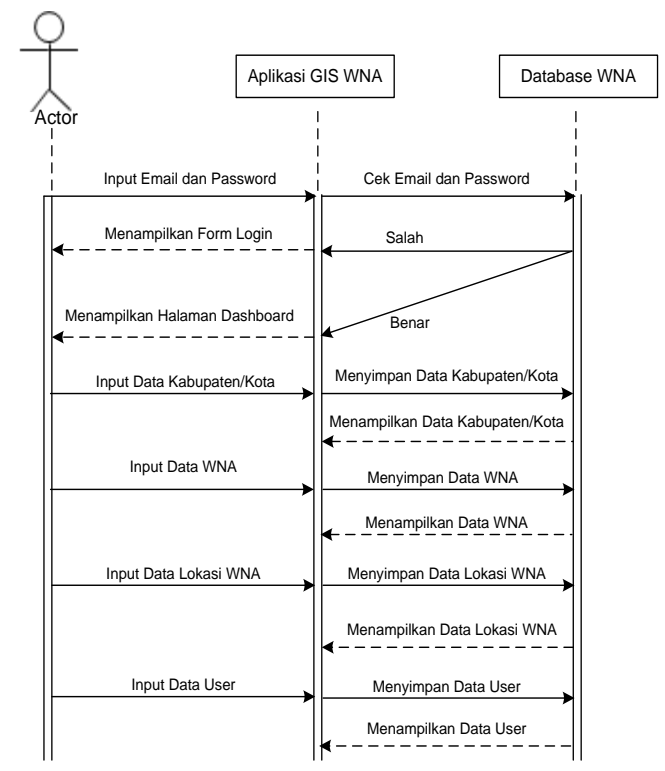

Gambar 6. Sequence Diagram

\section{Implementasi}

Implementasi sistem adalah tahapan yang dilakukan untuk menyelesaikan disain dalam merancang sebuah sistem yang telah disetujui serta menguji, menginstal dan memulai penggunaan sistem[5].

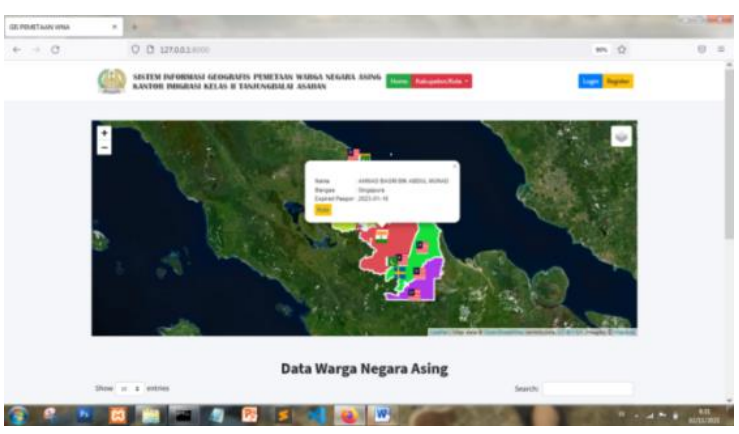

Gambar 7. Menu Home

Menu home yaitu untuk halaman pengunjung, dimana terdapat peta berdasarkan kabupaten/kota dan titik lokasi WNA, beserta informasinya.

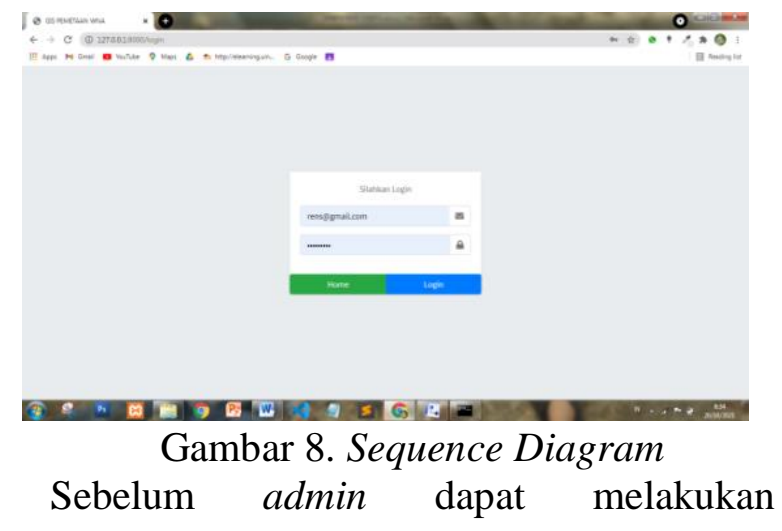

pengelolaan data WNA, admin harus login terlebih dahulu dengan memasukkan email dan password.

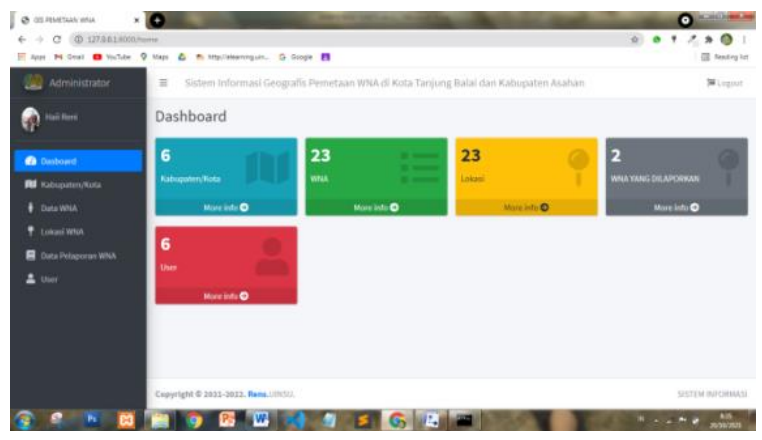

Gambar 9. Menu Dashboard

Gambar diatas merupakan halaman dashboard, halaman dashboard akan muncul ketika admin sudah melakukan login.

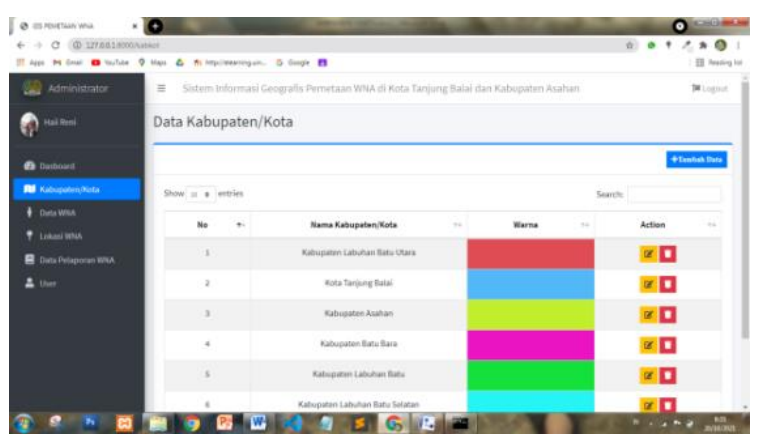

Gambar 10. Menu Data Kabupaten/Kota Gambar diatas merupakan halaman data Kabupaten/Kota, dimana halaman ini akan menampilkan data-data kabupaten/kota, dimana ada warna yang menjadi pembeda pada setiap kabupatem dan kotanya.

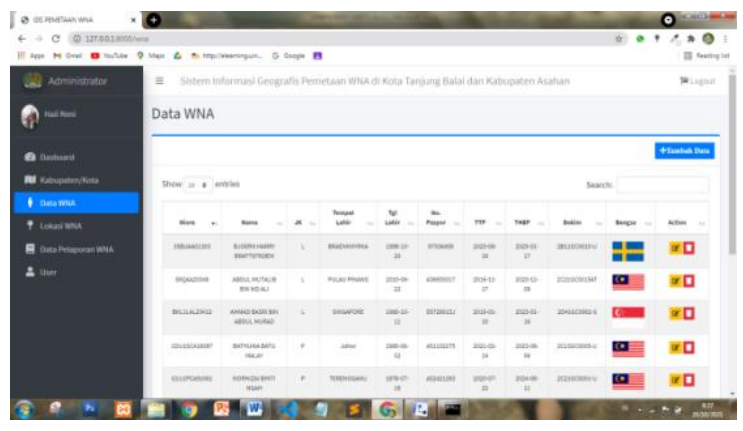

Gambar 11. Data WNA

Menu pengelolaan data WNA, yang dimana pada menu ini terdapat data-data WNA. 


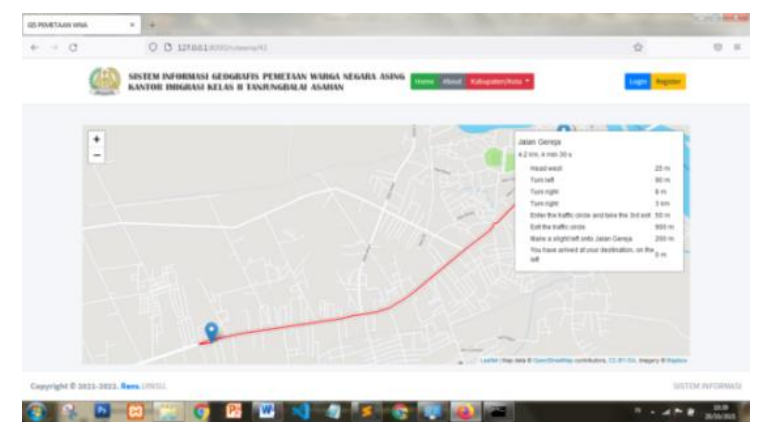

Gambar 12. Menu Rute

Menu rute merupakan jalan menuju lokasi WNA, dimana titik lokasi juga dapat diubahubah sesuai titik lokasi pengunjung berada.

\section{KESIMPULAN}

Berdasarkan hasil yang didapat dari peneltian yang dilakukan maka dapat disimpulkan :

1. Sistem yang dibangun sudah dapat membantu pelayanan Kantor Imigrasi Kelas II Tanjung Balai Asahan, dalam pengawasan orang asing atau WNA.

2. Sistem yang dibangun dapat memberikan informasi tentang persebaran WNA diwilayah tempat tinggal mereka, serta dapat melaporkan keberadaan WNA yang belum terdaftar

3. Sistem yang dibangun lebih baik dari penelitian sebelumnya, yaitu penelitian sebelumnya tidak menggunakan QGIS yang dalam menampilkan polygon sebagai pembeda disetiap daerahnya.

\section{DAFTAR PUSTAKA}

[1] Muhammad Arif, Ilka Zufria, and Ali Ikhwan. 2020. "Penerapan Metode Multilevel Feedback Queue Pada Sistem Informasi Pemesanan Paket Haji Dan Umrah Di PT.Aubaine Kabuhayan." Journal of Islamic Science and Technology 5(2): 12.

[2] Muslihudin, O. (2016). analisis dan perancangan sistem informasi menggunakan model terstruktur dan
$U M L$ (pp. 3-4). CV Andi Offset.

[3] Kurniawan, A., Suendri, \& Triase. (2019). Sistem Informasi Geografis Pemetaan Lokasi Panti Asuhan di Kota Medan. Journal of Islamic Science and Technology, 4(2), 119.

[4] Samsudin. (2018). Penentuan Penerimaan Remunerasi Dosen Dengan Rule Based Reasoning. Repository UINSU.

[5] Maniah, \& Hamidin, D. (2017). Analisis dan Perancangan Sistem Informasi ( $\mathrm{p}$. 111). Deepublish Publisher.

[6] Dj, W. N. M., \& Cahyono, A. B. (2016). Perancangan Sistem Informasi Geografis Zona Nilai Tanah Berbasis Web Menggunakan Leaflet Javascript Library. Jurnal Teknik ITS, 5(2), A810.

[7] Kurniawan, A., Suendri, \& Triase. (2019). Sistem Informasi Geografis Pemetaan Lokasi Panti Asuhan di Kota Medan. Journal of Islamic Science and Technology, 4(2), 119.

[8] Franto. (2020). Metode Pemetaan Potensi Mineralisasi Tiah Primer Dengan Penginderaan Jauh dan Sistem Informasi Geografis (pp. 60-63). Scopindo.

[9] Haekal Azief Haridhi. (2020). Buku Ajar Sistem Informasi Geografis Kelautan (2nd ed., p. 37). Syiah Kuala University Press.

[10]Hamidi Jasim. (2016). Hukum Keimigrasian Bagi Orang Asing di Indonesia (p. 45). Sinar Grafika. 